\title{
MedienPädagogik
}

Zeitschrift für Theorie und Praxis der Medienbildung

Special Issue Nr. 35:

Media literacy as intergenerational project: skills, norms, and mediation

Edited by Claudia Riesmeyer, Thorsten Naab,

Anne-Linda Camerini, Ruth Festl, and Christine Dallmann

\section{Editorial: Media literacy as intergenerational project: skills, norms, and mediation}

Claudia Riesmeyer, Thorsten Naab, Anne-Linda Camerini, Ruth Festl, and Christine Dallmann

The extensive research literature on media literacy is reflected by diverse theoretical conceptions, assumptions, and conclusions. Nevertheless, the considerations of numerous scholars in this «patchwork of ideas» (Potter 2010,676) revolve around the importance of critical thinking and the interplay of different generations in the acquisition of media literacy.

Many scholars argue that critical thinking is a key qualification for the reflection of possible risks and a media use oriented towards opportunities. The ability to use media critically is directly linked to democratic-theoretical considerations, where information (Buckingham 2007), knowledge (Potter 2010), and analytical skills (Koltay 2011) are defined as components of media literacy. Information and knowledge are necessary for gaining access to media offerings, to analyze and evaluate them, and to create own media content (e.g., a profile on social networking sites like Instagram; Livingstone and Helsper 2010). Definitions of media literacy are usually based on the ability to access media and on media knowledge as expertise. These skills are considered fundamental for a reflective and (self-)critical use of media (self-competence), and to pass one's own knowledge and abilities to others (social competence). However, previous research (e.g., Livingstone 2014) has also shown that deficits in media literacy lie less in knowledge, but rather in subsequent actions and thus in the transformation of knowledge into action. Knowledge does not automatically lead to a critical use of media or to a change in behavior (Martens 2010; Riesmeyer, PfaffRüdiger and Kümpel 2012; 2016). It is, therefore, not enough to only focus on knowledge, but respective actions must be considered as well when investigating media literacy and its mediation.

Following the idea of media literacy generations, researchers have discussed the acquirement of media literacy as a long-term process during life cycle (Potter 2010), since individuals need to adjust their media literacy to

- media changes and their media ecosystem,

- developmental challenges during different stages of their lives,

- their basic needs, and

- the turning points of their biographies. 
This process of media literacy socialization is individually shaped by diverse socialization agents, i.e. parents, teachers, peers, and the individual itself (Hobbs 2011), who aim to adapt skills and to mediate certain norms for a person's media use (Süss 2010). Consequently, living in different media landscapes and corresponding socializing environments lead to diverse media experiences (Naab \& Schwarzenegger 2017; UNESCO 2016) and highly individual sets of media literacy.

\section{Agents, generations, and media literacy: the concept of this special issue}

This special issue of MediaEducation examines the interplay of the aforementioned considerations about media literacy. The eight selected, peer-reviewed articles are based on presentations at two international conferences: In May 2018, international scholars visited the conference «Media literacy as intergenerational project: skills, norms and mediation» at the LMU Munich, a pre-conference of the 68th annual conference of the International Communication Association (ICA). In October 2018, the ECREA's temporary working group «Children, youth, and media» met at USI Università della Svizzera italiana and discussed about «Children and Adolescents in a Mobile Media World».

The compiled number of articles follows the idea of an entanglement of media changes, lifelong acquirement of media literacy, and exchange processes between media generations. They discuss the implications of this conceptualization of media literacy for growing up in a mobile media world from four perspectives:

First, from an individual perspective, three articles discuss the role of a person's skills in the process of media socialization. It is known that the individual has a share in media socialization (conceptualized as self-socialization or agency; Arnett, 1995, 2007) and that certain framework conditions guide how the individual develops abilities for her or his media use. Mareike Wieland compares how younger and older internet users search for information and, therefore, focuses on information literacy (search) skills. This information literacy depends on cognitive abilities such as monitoring and regulating the search process being considered as basic conditions of media literacy. Based on a qualitative, process-oriented approach, results show that the focused generation sometimes influences individuals' information literacy: younger participants (aged 16-26) use more productive strategies to collect information, while the completion of a complex task does not depend on age. Jee Young Lee and Didin Nuruddin Hidayat conduct a survey and examine how students access and implement information and communication technologies in their everyday college life. Students are portrayed as predominantly technically versed, and it is assumed that they also use media technologies to cope with educational tasks in college. The article elaborates on how these usage habits are linked with digital literacy and 
learning satisfaction. Based on qualitative interviews, Viviana Huțuleac and Delia Cristina Balaban analyze the media literacy of Romanian children, whose parents work abroad and who are not able to mediate media literacy at home but digitally supported (e.g., via smartphone). These children, on the one hand, are often faced with the challenge to adapt media literacy skills by their own. On the other hand, they live in a favorable economic context and have better access to communication technologies than their peers. The migration situation influences the motivational dimension of media skills but seems to have little influence on legal media skills. Social media offer technological support in order to see their parents as well as to share their problems and worries. It is often used for educational purposes in this particular situation.

These framework conditions of media literacy mediation lead to the second part of the special issue, i.e., the family as a socialization agent, its part in the socialization process, and its sense of responsibility regarding this role. Liane Rothenberger, Ahmed Elmezeny, and Jeffrey Wimmer focus on the use and the regulation of mobile media devices of children and adolescents in refugee families. Their results base on a qualitative approach and show that media use changed after arrival in Germany, partly attributed to the changing socio-cultural environment. Most children and adolescents tend to consume German media content more often than Arabic content. In the rare cases, in which they do consume Arabic media content, it is in the presence of their parents who state that they do so to bring their children closer to their roots. Parents and the nuclear family have an important role in imparting skills for this use of media. The role of the educational style in the development of the ability to reflect on media is examined in the article by Claudia Riesmeyer, Bernadette Abel, and Annika Großmann. They conduct qualitative interviews with adolescents and parents. The higher the warmth of parenting, the higher the children's ability to criticize the media. The influence of parental control is less clear. It is advantageous to a certain degree and helps children. However, if it becomes too strong, control unfolds a rather negative potential that inhibits young people's media literacy. Parents are not only central socialization agents but also role models: their media use shapes that of their children. Although parents consider online privacy as important, they insouciantly include personal information about their children online. Thorsten Naab suggests the concept of media trusteeship as an additional theoretical perspective to understand how parents shape the digital identity of their children. Based on indepth interviews with parents, the results of his research on social media indicate that parents are largely unaware of the described role duality between their own online privacy and the presentation of their children online. They are only partially able to foresee the consequences of their activities. The analysis identifies three distinct types of parental media trusteeship: While some parents shield their offspring 
from social media, others appear unable to respond adequately to the risks of social media activities or seem to ignore them completely. This article demonstrates that parents surveyed had no idea how to teach media literacy and guide their children to a safe and careful use of social media.

These findings illustrate the need for schools to impart media literacy. The third part of this special issue focuses on the schools' role in the process of media literacy mediation. Priscila Berger analyzes the conditions under which students rely on teachers to develop computer and information literacy (CIL). Her study explores the characteristics of students, schools, and countries that are associated with the incidence of learning CIL from teachers. Based on previous studies, she developed and tested a model employing a three-level analysis with data from 14 participant countries of the International Computer and Information Literacy Study (ICILS). The model reveals significant associations with students' socioeconomic conditions, self-efficacy in advanced ICT tasks, gender and countries' ICT Development Index score. However, the schools' characteristics do not significantly contribute to the model. Nevertheless, schools are important places for the adaption of media literacy skills especially when other socialization contexts do not do contribute to this task of mediation. In this regards, Annekatrin Bock and Felicitas Macgilchrist ask how schools today engage with mobile media. Drawing on ethnographically oriented research at German Schools Abroad, their article teases out three sets of practices regarding adolescents' mobile media use by identifying safe, enthusiastic, and postdigital schools. Presenting vignettes from these three schools to highlight each set of practices, the article shows how students are differently controlled, guided, and given space to shape their (media) worlds. The authors highlight the tensions when schools aim to guide adolescents' mobile use, arguing that each set of practices undermines itself. It also illustrates that more mobile media use in schools is not, as often assumed, a mark of progress, improvement, or modernity. Instead, the practices exist simultaneously. They enact different (not incremental) institutional priorities, and different (not incremental) understandings of adolescents' mobile use.

\section{References}

Buckingham, David. 2007. «Digital media literacies: Rethinking media education in the age of the Internet.» Research in Comparative and International Education, 2, 43-55.

Hobbs, Rene. 2011. «The State of Media Literacy: A Response to Potter.» Journal of Broadcasting and Electronic Media, 55 (3), 419-430.

Koltay, Tibor. 2011. «The media and the literacies: Media literacy, information literacy, digital literacy.» Media, Culture \& Society, 33, 211-221.

Livingstone, Sonia. 2014. «Developing social media literacy: How children learn to interpret risky opportunities on social network sites.» Communications, 39, 283-303 
Livingstone, Sonia, and Ellen Helsper. 2010. "Balancing opportunities and risks in teenagers' use of the internet: the role of online skills and internet self-efficacy.» New Media \& Society, 12 (2), 309-329.

Martens, Hans. 2010. «Evaluating media literacy education: Concepts, theories and future directions.» Journal of Media Literacy Education, 2 (1), 1-22.

Naab, Thorsten, and Christian Schwarzenegger. (2017). «Why aging is more important than being old. Understanding the elderly in a mediatized world.» Nordicom Review, 38, 93-107.

Potter, W. James. 2010. «The State of Media Literacy.» Journal of Broadcasting \& Electronic Media 54 (4): 675-696. https://doi.org/10.1080/08838151.2011.521462.

Pfaff-Rüdiger, Senta, Claudia Riesmeyer, and Anna Sophie Kümpel. 2012. «Media literacy and developmental tasks: a case study in Germany.» Media Studies, 3 (6), 42-56.

Riesmeyer, Claudia, Senta Pfaff-Rüdiger, and Anna Sophie Kümpel. 2016. «Wenn Wissen zu Handeln wird: Medienkompetenz aus motivationaler Perspektive.» Medien \& Kommunikationswissenschaft, 64 (1), 36-55.

Süss, Daniel. 2010. «Mediensozialisation zwischen gesellschaftlicher Entwicklung und Identitätskonstruktion.» In Mediensozialisationstheorien edited by Dagmar Hoffmann and Lothar Mikos. 109-130. Wiesbaden: VS.

UNESCO 2016. «Media and Information Literacy.» Electronic document: http://www.unesco. org/new/en/communication-and-information/media-development/media-literacy/milas-composite-concept/. 